\title{
NUTRITIONAL STATUS OF SCHOOL CHILDREN AGED 8-12 YEARS IN
} DEPRIVED AREAS OF MAURITIUS

\author{
Aurisinkala-Appadoo $S^{1}$, Oogarah-Pratap $B^{2}$ and A Ruggoo ${ }^{3 *}$
}

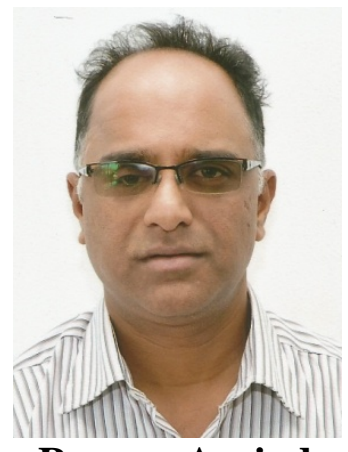

\section{Ruggoo Arvind}

*Corresponding author: aruggoo@uom.ac.mu

${ }^{\mathbf{1}}$ Faculty of Agriculture, University of Mauritius, Reduit, Mauritius

${ }^{2}$ Associate Professor, School of Applied Sciences, Mauritius Institute of Education, Reduit, Mauritius

${ }^{3}$ Associate Professor, Faculty of Agriculture, University of Mauritius, Reduit, Mauritius. 


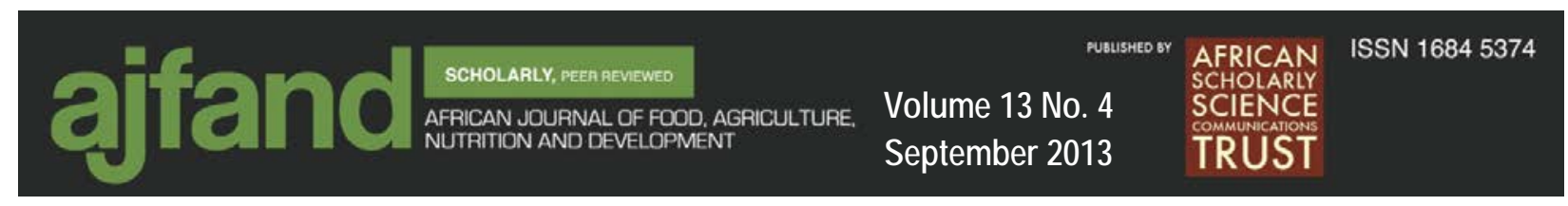

\section{ABSTRACT}

This study investigated the nutritional status of school children in deprived areas of Mauritius and determined whether specific socio-economic factors were associated with poor nutritional status among children. A cross-sectional survey was conducted among 240 primary school children aged 8-12 years old. Out of 27 schools located in the deprived regions of Mauritius, eight of them were selected for the study. The data collection tools included a questionnaire, anthropometric measurements (weight and height) and a 24-hour dietary recall. A questionnaire was used to gather information on the socioeconomic profile of the children and their eating patterns. The Centre for Disease Control (CDC) BMI-for-age and stature-for-age percentiles were used to identify children who were stunted $\left(<5^{\text {th }}\right.$ percentile stature-for-age), underweight $(<$ $5^{\text {th }}$ BMI-for age percentile), overweight ( $85^{\text {th }}$ to $95^{\text {th }}$ percentile BMI-for age) or obese $\left(\geq 95^{\text {th }}\right.$ percentile BMI-for-age). Findings revealed that the main meals taken by the children included breakfast, lunch and dinner. Ninety two percent of the children mentioned taking breakfast in the morning; the most commonly consumed food commodities being bread, margarine, cheese, jam and tea; milk, yoghurt, fruits or fruit juice were rarely consumed. Packed lunches consisted mainly of eggs and convenience foods such as sausages without any vegetables. Poor snacking habits, that is, high consumption of salty corn-based snacks, were identified among these children. Age of school children was significantly associated $(p<0.05)$ with the amount of money spent on snacks at school. Anthropometric measurements revealed the prevalence of both undernutrition and overnutrition among the children. Thirty seven per cent of the children were underweight, four per cent were overweight, three per cent were obese and there were no cases of stunting. The study findings indicate that the children are being fed the wrong kinds of foods or the wrong proportions. Thus, there is a need for local education and health authorities to develop nutrition education programmes that are contextually sensitive to specifically target school children and parents in deprived areas of Mauritius.

Key words: Nutritional status, deprived children, Mauritius 


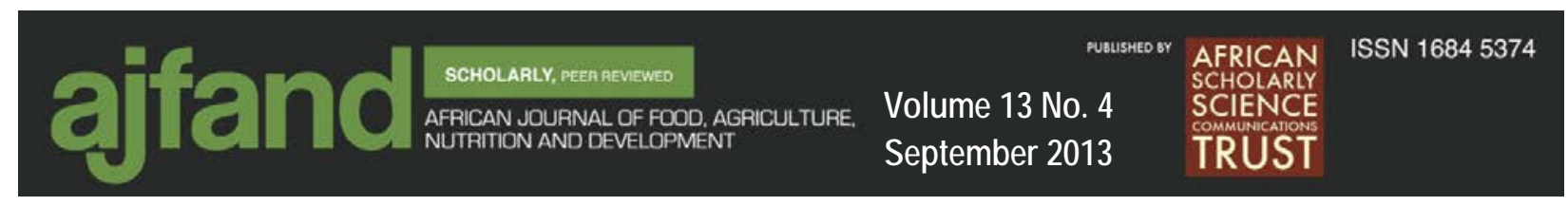

\section{INTRODUCTION}

Mauritius is an island of approximately 2000 square kilometres in the southern part of the Indian Ocean, and forms part of sub-Saharan Africa. It has over the past four decades, since its independence in 1968, developed from a low-income, agriculture based economy to a middle-income diversified economy with growing industrial, financial, Information and Communication Technologies (ICT), sea-hub and tourist sectors. It has a free market economy with positive economic growth and is considered as one of the most affluent nations in sub-Saharan Africa with a Gross National Income (GNI) per capita of USD 13.344 in 2008 compared to an average GNI per capita of USD 2,050 for the sub-Saharan African region [1]. Despite the socio-economic progress of the country, in the year 2006-2007, relative poverty, as measured by the proportion of households below the half median monthly household income per adult equivalent, was $7.9 \%$ in 2006/07; the proportion of poor persons in relative poverty was $8.5 \%$ during the same period [2]. Poor socio-economic status is a contributing factor to deprivation of good and sufficient nutrition in children of school going age [3]. Inadequate nutrient intake during childhood leads to undernutrition, which results in decreased cognitive function, growth failure, greater developmental delays, diminished resistance to infection and reduced adult size, leading to decreased economic productivity $[4,5,6,7]$. Undernutrition is responsible for more than one third of all child deaths worldwide [7]. The prevalence of underweight children between the ages of 5-11 years is 24.3\% in Mauritius [8].

Major contributors to childhood malnutrition are poverty, low levels of education and poor access to health services [7]. Increasing wealth is a cornerstone of malnutrition reduction. Improving the level of education of youngsters can assist in increasing the socio-economic profile of the nation, and hence contribute to poverty alleviation [9, 10]. The Zones d'Education Prioritaires' (Z.E.P) school project implemented in the year 2002 is one of the major initiatives of the government of Mauritius to improve the level of education of children [11]. Twenty seven schools were selected for the project and are located in the socio-economically deprived areas of Mauritius. The schools cater for needy children and their focus is mainly on remedial education and school food programme [9]. A large number of children attending these schools come from 25,000 households living below the relative poverty line in Mauritius [10]. These households have an average monthly income estimated to be Rs 7,055 (approximately USD 230) against Rs 22,242 (approximately USD 740) for all households in Mauritius [2]. Moreover, the children have poor access to nutritious food and this can contribute to delayed development of intellectual ability and increased rate of school absenteeism.

The nutritional status of children is a good indicator of health status of a community [12]. Nutritional status is defined as a measurement of the extent to which an individual's physiologic need for nutrients is being met [13]. Assessment of nutritional status of an individual involves biochemical tests, clinical observations, diet history and anthropometric data [3]. The three most often used anthropometric

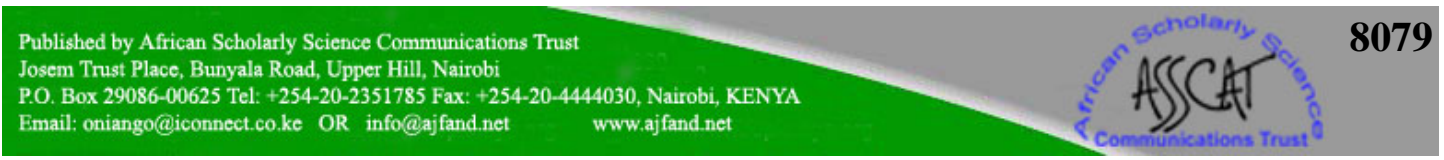




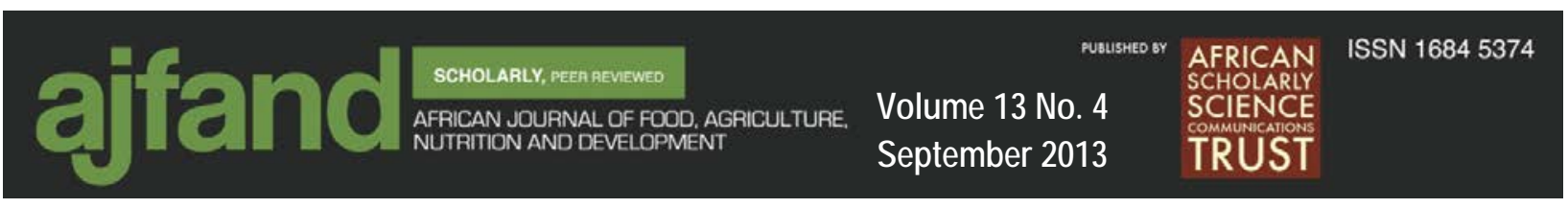

indices are weight-for- height, height-for-age, and weight-for-age. Values which fall below the $5^{\text {th }}$ percentile range give indication of wasting, stunting and underweight, respectively [14]. Individual nutritional status has been reported to vary on the basis of a person's living conditions, availability of the food supply, health and socioeconomic status [3]. Understanding the relationship between children's socioeconomic background and nutritional status is needed to develop effective intervention programmes [15].

Improvements in health and nutrition among disadvantaged children help in their cognitive development, and at a later stage would help in increasing work productivity, thus contributing to wealth creation. It has been shown that early nutritional improvements can have a powerful positive impact on the population's health, which is a prerequisite to economic development [6]. The study findings should help to increase the government's awareness of the prevailing nutritional problems among children from socio-economically deprived areas of Mauritius, and whether there is a need for improvements in nutrition education programmes and nutrition surveillance. The objectives of this study were thus to assess the nutritional status of children (8-12 years) in deprived areas of Mauritius and to determine the socio-economic factors associated with poor nutritional status of the children.

\section{RESEARCH METHOD}

\section{Sample selection}

There are 27 schools in Mauritius located in the deprived regions. Given the difficulty in accessing these schools, a convenience sample of eight schools was selected for the study. In each school, thirty students were chosen, ten ( 5 males, 5 females) from each of the three upper primary standards (4, 5, and 6). The total sample size was 240. Upper primary children were selected since they were cognitively more mature to complete the questionnaire.

\section{Survey instrument}

A questionnaire consisting of four different sections was designed to collect data and to meet the objectives of the study. It consisted of both open-ended and closed questions. Sections A, B and C gathered information about the socio-economic background of the children, eating patterns and anthropometric data, respectively. The socio-economic background was judged through occupation of parents rather than parents' monthly income. The occupations were classified as: managerial work, selfemployed or non-managerial work such as Export Processing Zone work, and manual work. It was assumed that young children would be able to report the occupation of their parents more accurately than the monthly income. In Section D, a 24 hour Food Recall was included to cross check information given on their daily food intake; foods taken during breakfast, lunch, dinner and in-between meals were noted. The 24 hour Food Recall was administered to a sub-sample which comprised 48 students from the selected schools; one girl and one boy from each standard in each school was chosen to complete the 24 hour Food Recall form.

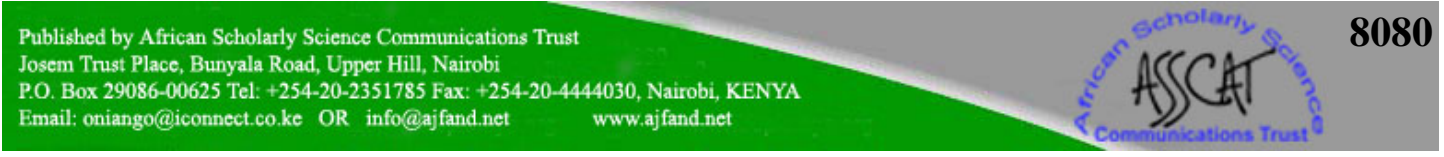




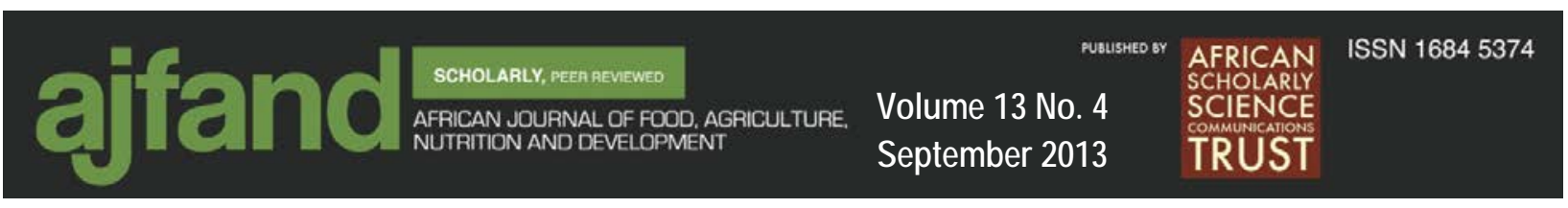

\section{Data collection}

Permission was sought from the Ministry of Education and Scientific Research prior to starting the data collection. Parental consent was also sought before collecting data from the children. Data were collected from January 2010 to February 2010. The questionnaire was administered to one student at a time, that is, each question was read and explained in Creole, the local language that is mostly understood by school children, without influencing their choice. This was done to increase the accuracy of the responses. The time taken per student for the filling of the questionnaire and for taking the anthropometric measurements was about 15 minutes. The questionnaire was structured in a simple way to be understood by the children. The weight in $\mathrm{kg}$ (read to the nearest $0.1 \mathrm{~kg}$ ) and height in $\mathrm{cm}$ (read to the nearest $0.5 \mathrm{~cm}$ ) was taken with a bathroom scale and a measuring tape respectively. During this activity, children were asked to remove their shoes and excessive clothing and to stand in an erect position so as to minimize errors in the measurements recorded.

\section{Data analysis}

Data were initially checked for inaccuracies and a coding book was subsequently devised. The Statistical Software, Statistical Package for Social Sciences (SPSS) version 13.0 was used to analyze the responses from the questionnaires. Relevant cross tabulations between variables of interest and Pearson's Chi-square test were used to reveal any significant association between variables of interest. Tables and charts were prepared using Microsoft Excel Version 2007.

For the anthropometric measurement determination, CDC charts were used as reference. There are separate growth charts for boys and girls aged 2-20 years. The charts contained standard growth curves and those denoted as percentiles were used to determine BMI-for-age and stature-for-age.

Each set of measurements was plotted as follows:

> For BMI-for-age, BMI $\left(\mathrm{kg} / \mathrm{m}^{2}\right)$ was plotted against age (years). BMI was first generated in excel by applying the formula and then individual data were plotted on the CDC growth chart.

$>$ For Stature-for-age, stature in $\mathrm{cm}$ against age (years) was plotted. If the point falls below the $5^{\text {th }}$ percentile, the child is considered as stunted.

Details on how the weight status was interpreted in terms of percentile range are given in Table 1.

\section{STUDY RESULTS}

\section{Socio-demographic profile}

A majority of children were from the Christian (64.2\%), followed by Hindu (17.5\%), Muslim (17.1\%) and Chinese communities (1.2\%). Nuclear family structure was most prevalent among the sample chosen $(77.1 \%)$. A significant association $(p<0.05)$ was found between ethnic group and the family set up of the children; a broken family

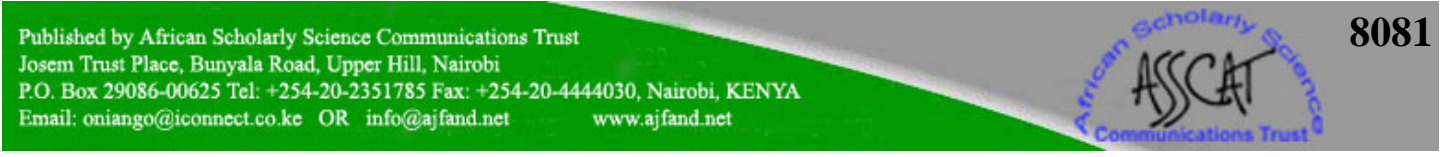




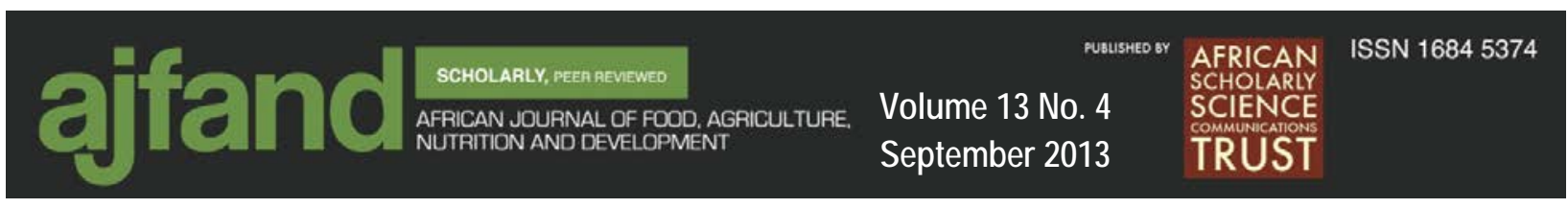

background was more prevalent within the Christian community. Concerning the type of occupation carried out by the parents, it was found from the study population that a high proportion of the fathers were manual workers (42.3\%) and almost half of the mothers were housewives (46.6\%).

\section{Eating patterns}

Findings about breakfast consumption revealed that the majority of children took breakfast (92.1\%) before coming to school. The most commonly consumed commodities were found to be bread (73.8\%) and margarine (67.9\%), followed by tea $(41.7 \%)$, which were taken together in the morning. Children also consumed cheese (32.5\%), jam (24.2\%) and breakfast cereals (23.3\%). Milk (6.7\%), fruit (8.3\%), yoghurt $(0.4 \%)$ and fruit juices (3.8\%) were consumed to a lesser extent. The type of food consumed during breakfast among the families of lower socio-economic status was also investigated. For example, it was found that bread consumption at breakfast was more popular than the consumption of breakfast cereals among children whose parents were manual workers (33\% for bread versus $9 \%$ for breakfast cereals).

A positive finding has been observed regarding packed lunches; most (96\%) of children brought their lunch box to school. The most popular energy giving food at lunch time was found to be bread (59.6\%). Children obtained their protein sources at lunch time from eggs (85.4\%), sausages (74.6\%), poultry (65\%), red meat (53.3\%), burgers (51.3\%), canned fish (44.6\%), and ham (43.3\%). The higher percentage of egg consumption reveals that children obtained their source of high biological value protein through cheap sources of protein available in Mauritius. A small percentage of children mentioned eating plant-based protein sources such as soya chunks (10.8\%). Diluted syrup, cordials and water were the most common beverages consumed by the children.

The most consumed energy giving food at dinner was rice with $84.5 \%$ of children reporting its consumption. It was found that convenience foods such as burgers, hams, sausages, and corned mutton/beef were hardly consumed at dinner. On the other hand, food products like meat, fish, eggs, poultry and pulses were more common at dinner (1-3 times weekly).

The most favorite snacks brought to school were found to be unhealthy foods, such as junk foods (salty corn-based snacks and chocolates) and sweets (see Figure 1). Only a small percentage of children brought healthy snacks such as dairy products (yoghurt/drinking yoghurt/cheese) or fresh fruits. 

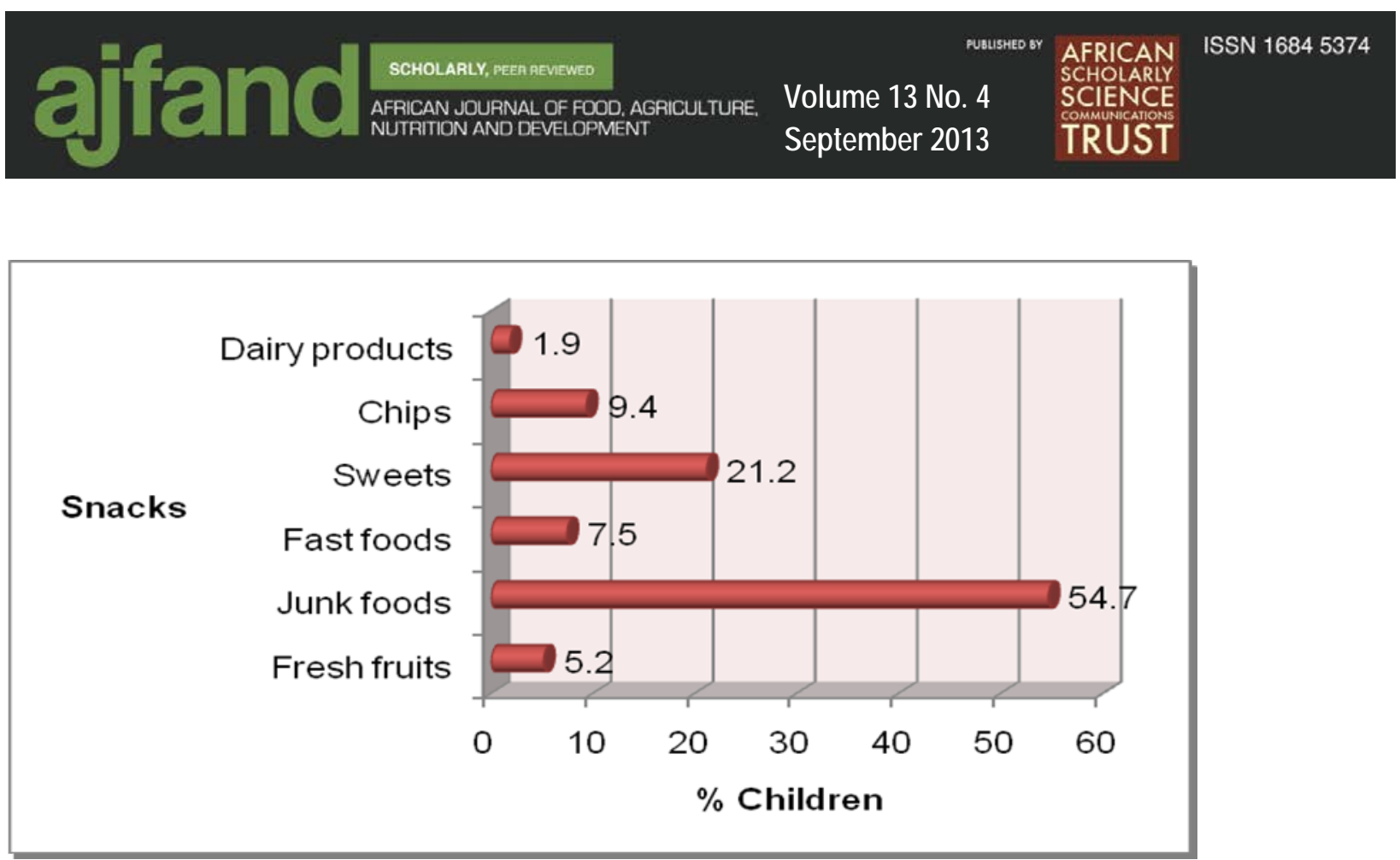

Figure 1: Types of snacks that children brought to school

A significant association $(\mathrm{p}<0.05)$ was found between the amount of money spent and the age of the school children. Older children spent more on the purchase of snacks. A higher percentage of children aged 12 years (42.9\%) spent more than Rs 15 (approximately USD 0.5 ) daily whereas $14.3 \%$ of children of the age of $8-9$ years spent more than Rs 15 (see Table 2).

\section{Weight and height status}

The majority of the children interviewed had a normal weight for height. Nonetheless, both problems of underweight and overweight were prevalent among the children (see Figure 2). More children were found to be underweight (36\% males, $38 \%$ females) than overweight or obese (7\% males, $5 \%$ females). Gender was not significantly associated $(\mathrm{p}>0.05)$ with weight status. Based on the stature-for-age percentiles, there was no case of stunting among the children. 

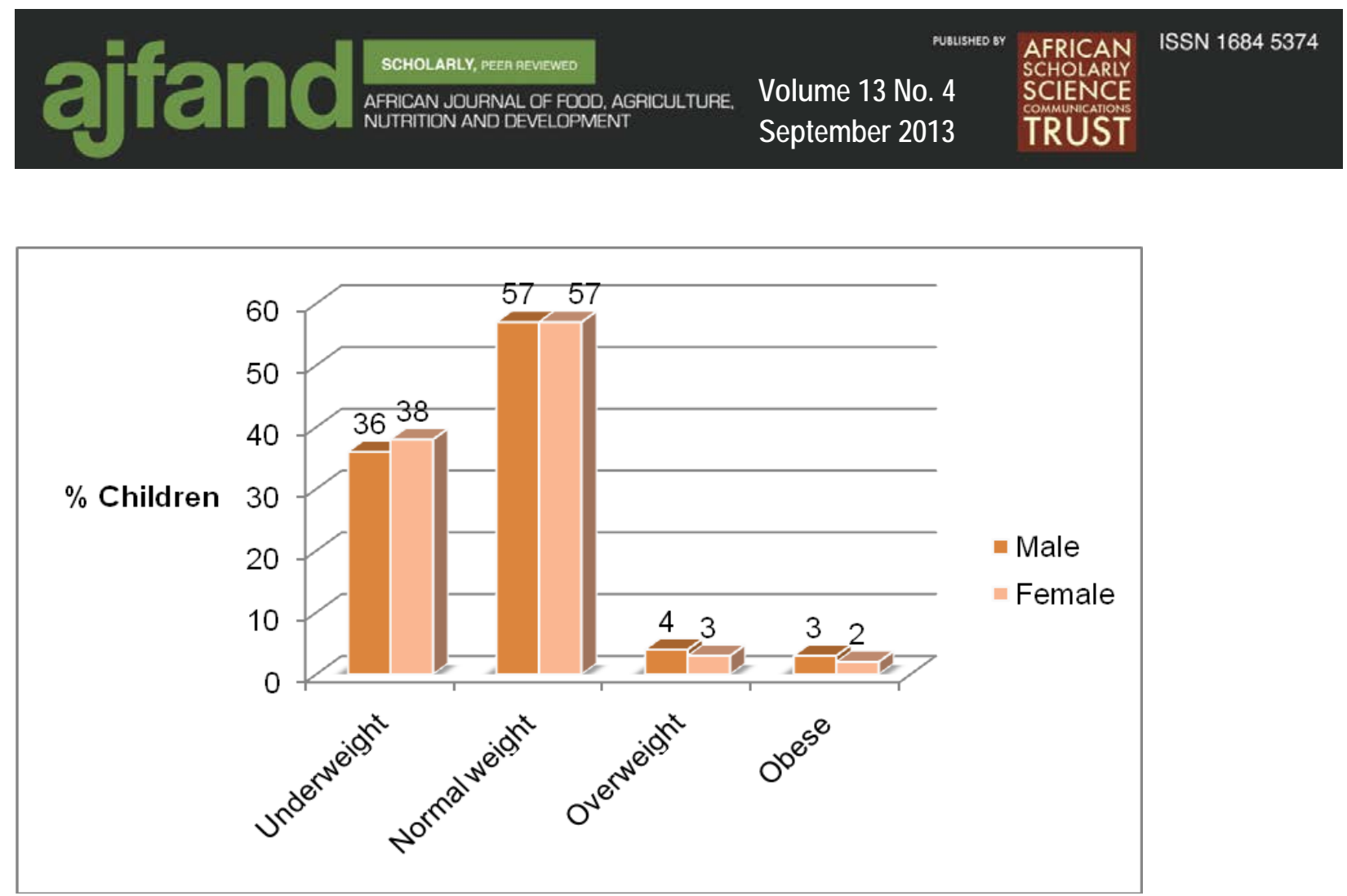

Figure 2: BMI-for-age status of children

\section{DISCUSSION}

\section{Breakfast pattern}

Breakfast is an indispensable meal. Consumption of breakfast can boost a child's diet by meeting the daily nutrient intake requirement, promoting healthful food choices and it is also associated with better academic performances [16]. In this study, 92.1\% of all children aged 8-12 years reported eating breakfast daily. The reason behind this positive dietary habit may be the high emphasis put on it by nutritionists during nutrition education carried out in the primary schools and the inclusion of topics on healthy eating and importance of breakfast in the school curriculum right from standard two (children around 6 years old). Accustoming children to regular breakfast consumption and to maintaining such behavior throughout the lifespan may have a beneficial health impact [17]. On the other hand, a small percentage of children skipped breakfast owing to factors such as waking up late, nothing available to eat, no one at home, and some of them disliked eating in the morning. It can be deduced that factors at the household level, for instance when parents are out at work or do not prepare anything in the morning, have a negative impact on the breakfast habits of the children.

A study carried out among the Mauritian youth revealed that the breakfast of Mauritians constituted of a loaf of bread, margarine, tea or milk, cereals and sometimes fruits [18]. Data gathered during this survey showed similar trends. The majority of children took bread with margarine and occasionally with cheese or jam. The main types of breakfast cereals consumed by children included bran, chocolate flavored and corn based. These are sold at a relatively high price, which may explain why this study found low consumption of breakfast cereals among children whose 


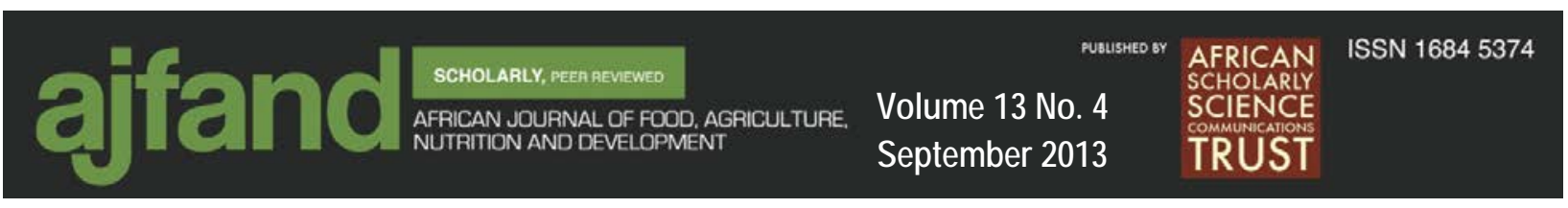

parents were manual workers. Moreover, it is interesting to note that a high percentage of children took breakfast cereals with tea rather than with milk. Another dietary habit observed in this study was the relatively low consumption of milk (6.7\%) and fruit (8.3\%) by children during breakfast. Milk is an excellent choice particularly for children between the ages of 8-12 years, since it contains most of the necessary nutrients (energy, protein, essential fatty acids, calcium and certain vitamins) necessary for a child to achieve full growth potential and to be active during the day. The fruit commonly consumed at breakfast time is banana, which is sold at a cheap price and is available in almost every shop in the country throughout the year. Low consumption of milk and fruits can be attributed to lack of nutrition knowledge by parents. In this study, a large proportion of the fathers were engaged in manual work and the majority of mothers were housewives, thereby reflecting parents' low level of education, including poor nutrition knowledge. In addition to it, it can also be observed that yoghurt and fruit juices are consumed to a lesser extent at breakfast. This can be explained by the fact that these food commodities are expensive and parents cannot afford to buy them for their children on a daily basis. It could also be that some of the poorer families do not have refrigerators to store dairy products such as milk and yoghurt.

\section{Lunch Pattern}

Packed lunches play an important role in the dietary intake of children. Almost all children (96\%) brought their packed lunch to school and this is considered a good practice. Lunch comprised mainly energy providing foods, mainly bread (59.6\%). Noodles, chapatti (flat bread made with whole wheat flour and water), pasta and rice were brought once per week by fewer children. It is interesting to point out that rice consumption at lunch was more prevalent among the Muslim children. Findings tend to indicate that respondents consumed lots of animal protein foods. The safe level of protein for children aged between $8-12$ years is $0.98-1.01 \mathrm{~g} / \mathrm{kg}$ body weight per day [19]. The main popular protein sources included eggs (85.4\%), sausages (74.6\%), poultry (65\%), meat (53.3\%), burgers (51.3\%), canned fish $(44.6 \%)$, and ham (43.3\%). A smaller percentage of children mentioned eating plant based protein sources such as soya chunks (10.8\%). Convenience foods such as sausages, burgers, ham and canned tuna are on the rise compared to home-made foods and this may be explained by the fact that they are easily available in supermarkets and many retail stores, and they can be prepared quickly and easily. Mauritius is self-sufficient in poultry and its products are successfully introduced in Mauritius to meet the change in eating habits of the Mauritian people. The poultry subsector in Mauritius is dominated by the production of broiler meat and table eggs [20]. Increased availability has resulted in a rise in consumption of poultry and its products. Although the total protein intake may not be a problem among these children, the high salt and fat content of these processed foods is cause for concern.

Diluted syrup, cordials and water were the most common drinks of children. Diluted syrup and most of the cordials, providing “empty-calories”, were taken by $62.9 \%$ of the children at least one to three times per week. This may be explained by factors

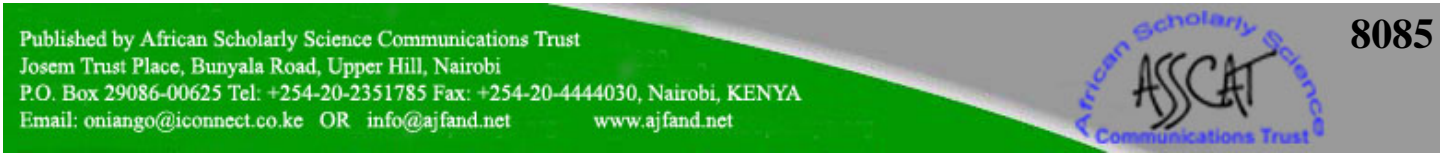




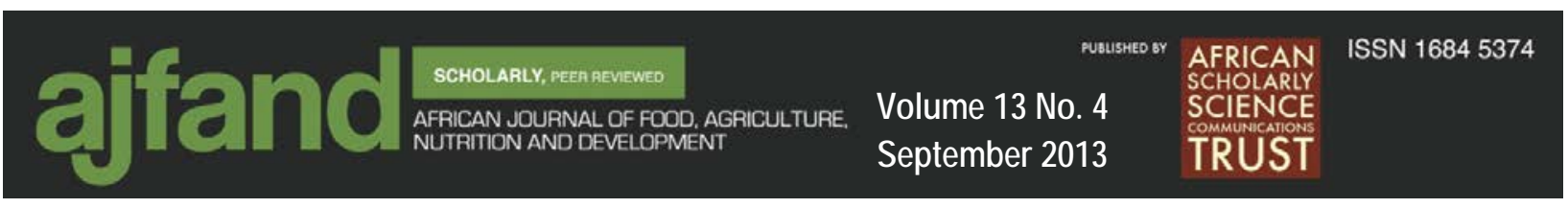

such as higher preferences for sweet drinks or peer pressure. The Ministry of Health and Quality of Life has recently banned the sale of fizzy drinks in all school canteens as a measure to combat non-communicable diseases such as obesity and diabetes in Mauritius. In this study, none of the children reported drinking carbonated drinks at school.

\section{Snacking pattern}

Snacks were found to play an important part in the diets of these children. However, the choice of snacks was a cause for concern. The most commonly consumed snacks by children were salty corn-based snacks (54.7\%), sweets, potato crisps, and chocolates. Healthy snacking of nutrient dense foods such as dairy products (1.9\%), fresh fruits (5.2\%), and bread with vegetarian/ non-vegetarian filling were the least popular snacks consumed by the children. These findings support those from the study conducted by Oogarah-Pratap and Heerah-Booluck [21] on the children's consumption of snacks at school in Mauritius; they also pointed out that upper primary children (8-12 years) tended to opt for snacks which are loaded with salt, sugar, energy and fat [21]. The availability of such snacks and their low prices make it possible for children to obtain them. However, corrective measures have been initiated by the Ministry of Health and Quality of Life since January 2010 to control the nutritional quality of snacks in school canteens. According to the Sale of Food on Premises of Educational Institutions Regulations 2009, a new list of food products that are authorized to be sold within the school premises has been devised. Some examples of the food commodities include: pancakes, fresh fruits, puddings, ricebased cakes, boiled maize and sweet potato. Nonetheless, unhealthy snacks are still widely available in many retail stores in Mauritius, and children can easily procure these. Therefore, it is up to the parent to impart the right knowledge as well as healthy food habits to children.

A significant association $(\mathrm{p}<0.05)$ was noted between age of children and the amount of money spent on the purchase of snacks. Older children (12 years old) reported spending more money on snacks. A similar trend was observed in the study by Oogarah-Pratap and Heerah-Booluck [21] on the children's consumption of snacks at school in Mauritius [21]. This difference can be partly explained by the lower food intake of younger children and the fact that parents tend to give more money to older children.

\section{Weight and Height status}

Body Mass Index is a statistical measurement which compares a person's weight with height and is used to estimate how much body fat a person has, whereas weight-forage indicator reflects body mass relative to chronological age and is influenced by both the height of the child (height- for- age) and weight-for-height [22, 23]. Upon computation of the BMI, although most children were found to have a healthy weight, 37 per cent of children were found to be underweight, using the CDC categories for BMI. Another four percent of children were found to be overweight and three percent were found to be obese. The findings indicate that underweight is more of a problem

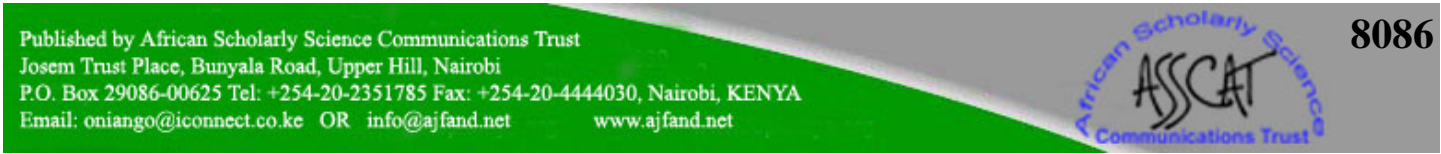


than overweight. A survey carried out by the Ministry of Health and Quality of Life in Mauritius in the year 2009 revealed that the prevalence of underweight children is higher among children. Weight of children depends on several factors such as daily activities, genetic predisposition, that is, parental weight, socioeconomic factors, infection and energy input /output. The weight of children reflects their dietary pattern or their energy intake. The meals mostly consumed by these children included breakfast, lunch, snacks and dinner. The quality of foods given during these meals may have an influence on the children's weight status. The majority of the children were found to fall between the $5^{\text {th }}$ and $95^{\text {th }}$ percentile for stature-for-age and there was no single case of stunting. The findings about the eating patterns of the children support the notion that their protein intake was adequate.

\section{CONCLUSION AND RECOMMENDATIONS}

This research investigated the nutritional status of children aged 8-12 years old from socio-economically deprived areas of Mauritius. These children constitute an at-risk group for malnutrition. Although most children reported eating three meals a day and snacks at schools, the nutritional quality of the foods consumed is a cause for concern. The children were either consuming the wrong kinds of foods or were consuming the energy-dense foods in large amounts. Consumption of fruits, vegetables and dairy products was rather low, and the most popular snacks consumed at school were energy-dense. These findings corroborate the findings on the weight status of the children. Malnutrition, in terms of both undernutrition and overnutrition, was prevalent among these children, with the problem of underweight being more significant. The Ministry of Health and Quality of Life in collaboration with other stakeholders is already involved in nutrition education campaigns using mass media to target the population at large. Nonetheless, there is a need for the health authorities to develop nutrition education programmes that target, specifically, school children and parents in deprived areas of Mauritius. School food programmes could be implemented to provide nutrient-dense foods fortified with essential vitamins and minerals. Such programmes could be financed through taxation of the upper socioeconomic class of the society or through the corporate social responsibility (CSR) scheme of private companies. Further studies that quantify the nutrient intakes of the children from socio-economically deprived areas are also warranted based on the findings of this study. 
Table 1: Interpretation of weight status in terms of Percentile range for BMI [23]

\begin{tabular}{ll}
\hline Weight status category & Percentile range \\
\hline Underweight & Less than the $5^{\text {th }}$ Percentile \\
\hline Healthy weight & $\begin{array}{l}\text { 5th percentile to less than the } \\
\text { percentile }\end{array}$ \\
\hline Overweight & \begin{tabular}{l} 
85th to less than the 95th percentile \\
\hline Obese
\end{tabular} \\
\hline
\end{tabular}

Table 2: Amount of money spent per day according to age

\begin{tabular}{|lllcc|}
\hline $\begin{array}{l}\text { Age of children } \\
\text { (Years) }\end{array}$ & \multicolumn{4}{c|}{ Spending } \\
\cline { 2 - 5 } & Rs 1-5 & Rs 5-10 & Rs 10-15 & > Rs 15 \\
\hline $\mathbf{8}$ & $38.5 \%$ & $29.2 \%$ & $22.5 \%$ & $14.3 \%$ \\
\hline $\mathbf{9}$ & $30 \%$ & $29.2 \%$ & $35.5 \%$ & $14.3 \%$ \\
\hline $\mathbf{1 0}$ & $25.7 \%$ & $27.4 \%$ & $29 \%$ & $28.6 \%$ \\
\hline $\mathbf{1 1}$ & $2.9 \%$ & $7.5 \%$ & $6.5 \%$ & $0 \%$ \\
\hline $\mathbf{1 2}$ & $2.9 \%$ & $6.6 \%$ & $6.5 \%$ & $42.9 \%$ \\
\hline
\end{tabular}




\section{REFERENCES}

1. United Nations Development Program (UNDP) Human Development Report 2010: 20 ${ }^{\text {th }}$ Anniversary Edition. UNDP, New York, 2010.

2. Central Statistical Office (CSO). Poverty Analysis 2006/07. CSO, Mauritius, 2009.

3. Akhtar MS, Bhatty N, Sattar M and MT Javed Comparison of Nutritional Status in Children of Different Socio-economic Statuses. Medical Journal of Islamic Academy of Sciences 2001; 14 (3): 97-102.

4. Sarma RKV Micronutrients - An Essential Aid to Daily Growth in Children. Indian Pediatrics 2009; 46: 12-19.

5. Mukherjee MR, Chaturvedi LS and R Bhalwar Determinants of Nutritional Status of School Children. Medical Journal Armed Forces India 2008; 64 (3): 227-231.

6. Iram $\mathbf{U}$ and SM Butt Understanding the Health and Nutritional Status of Children in Pakistan: A study of the Interaction of Socioeconomic and Environmental Factors. International Journal of Social Economics 2006; 33 (2):111-131.

7. United Nations Children's Fund (UNICEF). Progress for Children: A Report Card on Nutrition. UNICEF, New York, 2006.

8. Ministry of Health and Quality of Life (MOHQL) National Plan of Action for Nutrition 2009-2010. MOHQL, Mauritius, 2009.

9. Schools and Health Improved Learning through Better Health, Nutrition and Education for the School-Age Child. Partnership for Child Development, 2009.

10. Ministry of Education, Culture and Human Resources A New Strategy Built on Partnerships. Mauritius, 2009.

11. Ministry of Education, Culture and Human Resources ZEP- Mauritius Inclusive and Integrated Education. Mauritius, 2009.

12. Chakraborty U, Chowdhry SD, Dutta G and T Ghosh A Comparative Study of Physical Growth and Nutritional Status in Santal Children of Ghatsila and Bolpur. Tribes and Tribals 2008; 2: 79-86.

13. Mahan KL and ES Stump Krause's Food, Nutrition, \& Diet Therapy. Elsevier Health Sciences, USA, 2000. 
14. Gorstein J, Sullivan K, Yip R, de Onis M, Trowbridge F, Fajans P and G Clugston Issues in the Assessment of Nutritional Status using Anthropometry. Bulletin of the World Health Organization 1994; 72 (2): 273283.

15. Madhavan S and N Townsend The Social Context of Children's Nutritional Status in Rural South Africa. Scandinavian Journal of Public Health 2007; 35 (69):107-117.

16. Rampersaud GC Benefits of Breakfast for Children and Adolescents. American Journal of Lifestyle Medicine 2009; 3 (2): 86-103.

17. Giovannini $\mathbf{M}$, Agostoni $\mathbf{C}$ and $\mathbf{R}$ Shamir The Relevance of Breakfast: Concluding Remarks. Critrical Reviews in Food Science and Nutrition 2010; 50 (2): 129.

18. Ministry of Health/ UNICEF/WHO/IRDC Survey on Diet Health and Lifestyle of Youth in Mauritius. Ministry of Health, Port Louis, 1991.

19. FAO/WHO/UNU. Energy and Protein Requirements. World Health Organization-Geneva, 1985.

20. Rajkomar B and F Driver Poultry Sub-sector in Mauritius. FANRPANZimbabwe, 2003.

21. Oogarah-Pratap B and BJ Heerah-Booluck Children's consumption of Snacks at School in Mauritius. Nutrition and Food Science 2005; 35 (1):1519.

22. United Nations Development Group (UNDG) Prevalence of Underweight Children Under Five Years of Age. UNDG, New York, 2003.

23. Centers for Disease Control (CDC) About BMI for Children and Teens: Division of Nutrition, Physical activity and Obesity. CDC, USA, 2009. 